\title{
Spatially Confined Redox Chemistry in Periodic Mesoporous Hydridosilica-Nanosilver Grown in Reducing Nanopores
}

\author{
Ömer Dag, ${ }^{,+}$Eric J. Henderson, ${ }^{\ddagger}$ Wendong Wang, ${ }^{\ddagger}$ Jennifer E. Lofgreen, ${ }^{\ddagger}$ Srebri Petrov, ${ }^{\ddagger}$ \\ Peter M. Brodersen, ${ }^{\S}$ and Geoffrey A. Ozin ${ }^{*, *}$ \\ ${ }^{\dagger}$ Department of Chemistry, Bilkent University, 06800, Ankara, Turkey \\ ${ }^{\ddagger}$ Materials Chemistry and Nanochemistry Research Group, Centre for Inorganic and Polymeric Nanomaterials, Chemistry Department, \\ 80 St. George Street, University of Toronto, Toronto, Ontario M5S 3H6, Canada \\ ${ }^{\S}$ Surface Interface Ontario (SIO), University of Toronto, 200 College Street (Room 111), Toronto, Ontario M5S 3E5, Canada \\ S Supporting Information
}

ABSTRACT: Periodic mesoporous hydridosilica, PMHS, is shown for the first time to function as both a host and a mild reducing agent toward noble metal ions. In this archetypical study, PMHS microspheres react with aqueous $\operatorname{Ag}(\mathrm{I})$ solutions to form $\operatorname{Ag}(0)$ nanoparticles housed in different pore locations of the mesostructure. The dominant reductive nucleation and growth process involves $\mathrm{SiH}$ groups located within the pore walls and yields molecular scale $\operatorname{Ag}(0)$ nanoclusters trapped and stabilized in the pore walls of the PMHS microspheres that emit orangered photoluminescence. Lesser processes initiated with pore surface $\mathrm{SiH}$ groups produce some larger spherical and worm-shaped $\mathrm{Ag}(0)$ nano-

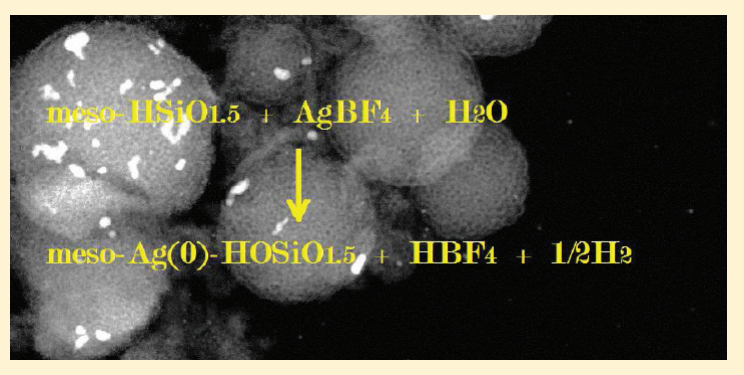
particles within the pore voids and on the outer surfaces of the PMHS microspheres. The intrinsic reducing power demonstrated in this work for the pore walls of PMHS speaks well for a new genre of chemistry that benefits from the mesoscopic confinement of $\mathrm{Si}-\mathrm{H}$ groups.

\section{INTRODUCTION}

Since the discovery of surfactant-templated periodic mesoporous silica (PMS), ${ }^{1}$ nearly two decades of research has yielded a vast array of differently functionalized periodic mesoporous materials, including the periodic mesoporous organosilicas (PMOs), ${ }^{2}$ hybrid periodic mesoporous organosilicas (HPMOs), ${ }^{3}$ bifunctional periodic mesoporous organosilicas (BPMOs), ${ }^{4}$ and recently molecularly imprinted mesoporous organosilicas (MIMOs). ${ }^{5} \mathrm{~A}$ common motivating force in the synthesis of these materials has been the search for new functionality and improved applications, whether derived from their form exemplified by fibers, spheres, tubes, films, monoliths, and lithographic patterns, physical properties such as dielectric constant, mechanical strength, or hydrophobicity, pore morphology including hexagonal, cubic, worm, or lamellar, chemical properties of functional groups anchored within the mesopores, and host-guest interactions that can be tailored via the chemical composition of the host. ${ }^{6}$

One particularly interesting area of application of PMS and PMO materials is as solid supports for nanoscale metals such as silver nanoclusters and nanoparticles important in (photo)catalytic, optical, and biological applications. ${ }^{7-19}$ Although metallic nanoparticles are not usually known for their efficient emission properties due to quenching by conduction electrons, the highly efficient photoluminescence (PL) observed from molecular silver nanoclusters is exceptional and makes them attractive for optical and biomedical devices. ${ }^{11-17}$ By contrast, bulk and nanocrystalline forms of silver are only weakly photoluminescent with very low quantum efficiencies of
$10^{-8} \%$ and $10^{-2} \%$, respectively. ${ }^{20,21}$ The development of synthetic methodologies for accessing highly emissive metallic nanoclusters is essential to fully study and exploit their optical properties.

Creating few-atom silver clusters and stabilizing them in matrices such as rare gas solids, polymers, and zeolites has a long history and is an ongoing challenge. ${ }^{22}$ Mesoporous silica materials in many forms have been functionalized with silver nanoparticles using various methods. ${ }^{23-29}$ These include direct incorporation of silver ions into the channels of mesoporous silica by simple impregnation, pore surface modification by creating silver ion binding sites, and liquid crystalline templating. ${ }^{23-29}$ In all of these synthesis methods, $\mathrm{Ag}^{+}$ions are encapsulated in the pores and then transformed to $\operatorname{Ag}(0)$ by a reducing agent or a thermal post treatment. There have also been many attempts to create mesoporous materials with reducing agents that are chemically anchored to the channel walls. ${ }^{30}$ While modifying mesoporous silica with such tethered reducing agents requires tedious steps, it has been shown to produce uniform Ag nanoparticles and nanowires in the channels. ${ }^{30,31}$ An attractive alternative would be to find a way to create intrinsic reducing sites that are an integral part of the as-synthesized mesoporous silica, thereby simplifying the overall system. This is the focus of the present study.

Received: $\quad$ August 7, 2011

Published: September 26, 2011 
Scheme 1. Schematic Representation of the Outcome of Reacting Aqueous Ethanol Solutions of $\operatorname{Ag}(\mathrm{I})$ Salts with Periodic Mesoporous Hydridosilica (PMHS) ${ }^{a}$

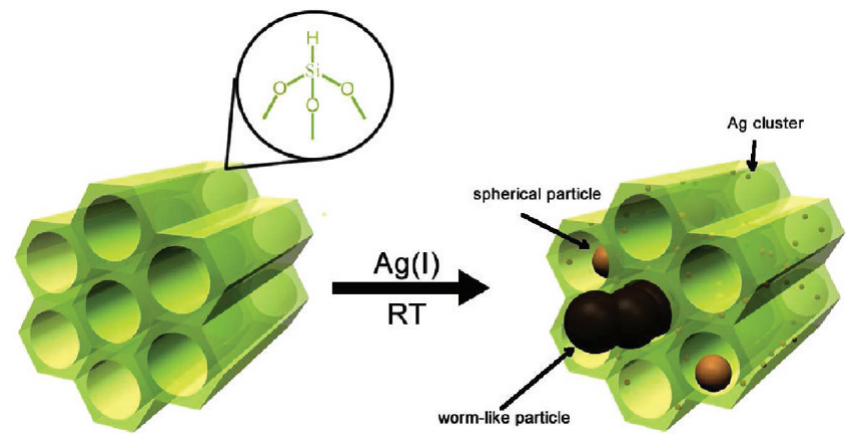

${ }^{a}$ The intermediate size brown spheres represent spherical-shaped $\mathrm{Ag}(0)$ nanoparticles in the pores, the small orange spheres represent molecular $\operatorname{Ag}(0)$ nanoclusters embedded within the pore walls, and the black objects represent large worm-shaped $\operatorname{Ag}(0)$ nanoparticles in the pores, the latter being comprised of smaller interconnected $\operatorname{Ag}(0)$ nanoparticles.

In this context, the recently discovered "impossible" periodic mesoporous hydridosilica (PMHS) host ${ }^{32}$ uniquely provides reducing hydride sites throughout the pore walls and covering the pore surfaces: every silicon atom in the material is bonded to hydridic hydrogen. This offers new opportunities for host-guest redox chemistry within a confined mesoscopic space. By "impossible", we mean that the fully interrupted three-dimensional porous solid PMHS should not exist; it should be thermodynamically unstable and prone to mesostructural collapse. However, we have shown that PMHS is indeed remarkably stable and its robustness facilitates investigations of its chemistry. Accessible hydridic functional groups that are an intrinsic part of the host framework enables reducing reactions of guests imbibed within the pores to occur that were not before considered possible.

In the investigation described herein, we demonstrate for the first time that photoluminescent molecular Ag nanoclusters can be synthesized as the dominant product by reducing $\mathrm{Ag}^{+}$ions via $\mathrm{SiH}$ groups located within the pore walls of PMHS, while plasmonic Ag nanoparticles in the form of spheres and worm shapes to a lesser extent are formed from $\mathrm{SiH}$ groups situated on the internal and external pore surfaces of PMHS.

To amplify, powder samples of PMHS with the morphology of microspheres were synthesized using $\mathrm{HSi}\left(\mathrm{OCH}_{2} \mathrm{CH}_{3}\right)_{3}$ as a silica source and P123 as a structure-directing agent (SDA) in aqueous acidic media. After SDA removal, the PMHS was reacted with solutions of various concentrations of $\mathrm{AgNO}_{3}$ or $\mathrm{AgBF}_{4}$ in water-ethanol mixtures for varying amounts of time. These reactions caused the reduction of $\mathrm{Ag}(\mathrm{I})$ and resulted in the deposition of $\operatorname{Ag}(0)$ nanoclusters and nanoparticles with different sizes and shapes in different locations within the PMHS host framework. The results of this study demonstrate that two different kinds of nucleation and growth processes are operative in PMHS that provide location specific size and shape control of $\operatorname{Ag}(0)$ nanoclusters and nanoparticles as envisioned in Scheme 1.

\section{EXPERIMENTAL SECTION}

2.1. Synthesis of Periodic Mesoporous Hydridosilica Microspheres. Microspheres of periodic mesoporous hydridosilica (PMHS) were synthesized by modifying the original procedure in the literature. ${ }^{32}$ A clear solution of $0.52 \mathrm{~g}$ of $\mathrm{P} 123\left(\mathrm{EO}_{20} \mathrm{PO}_{70} \mathrm{EO}_{20}\right.$, EO is ethylene oxide and $\mathrm{PO}$ is propylene oxide) in $15 \mathrm{~mL}$ of water was acidified with $0.25 \mathrm{~mL}$ of $1 \mathrm{M} \mathrm{HCl}$ (or $30 \mathrm{mg}$ of concentrated $\mathrm{HNO}_{3}$ ). $\mathrm{HSi}\left(\mathrm{OC}_{2} \mathrm{H}_{5}\right)_{3}(2.0 \mathrm{~mL})$ was added at once and shaken well to disperse the particles that formed immediately. Sphere growth was then allowed to occur in the undisturbed solution at room temperature for 2-3 days. The resultant PMHS microspheres were collected by centrifugation, directly suspended in $40 \mathrm{~mL}$ of an ethanol solution acidified with $1.0 \mathrm{~mL}$ of $1 \mathrm{M} \mathrm{HCl}$, and stirred for $24 \mathrm{~h}$ to remove the surfactant from the PMHS. The resulting powder was collected by centrifugation and dried in a $50{ }^{\circ} \mathrm{C}$ vacuum oven for $10 \mathrm{~h}$.

2.2. Reaction of $A g(I)$ with PMHS. For silver loading, $0.2 \mathrm{~g}$ of the PMHS was dispersed in $5 \mathrm{~mL}$ of ethanol at room temperature, and then $\mathrm{AgNO}_{3}$ or $\mathrm{AgBF}_{4}$ (dissolved in water) was added to the mixture. Upon addition of the $\mathrm{Ag}^{+}$source, significant $\mathrm{H}_{2}$ bubbling was observed. The reaction was carried out for between $5 \mathrm{~min}$ and $1 \mathrm{~h}$ until the evolution of $\mathrm{H}_{2}$ stopped. The mixture was filtered to obtain a powder sample, which was then washed several times with ethanol. The silver-loaded powder sample was allowed to dry at room temperature.

2.3. Materials Characterization. Raman spectra were collected using LabRam 300 confocal micro-Raman spectrometer equipped with a $532 \mathrm{~nm}$ diode laser, electronically cooled CCD camera, 1200 grazes $/ \mathrm{mm}$ monochromator. The spectrometer was calibrated using a crystalline silicon wafer. Powder X-ray diffraction (PXRD) patterns were obtained using a Siemens $\mathrm{D} 5000$ with $\mathrm{Cu} \mathrm{K} \alpha$ radiation $(\lambda=0.15418 \mathrm{~nm})$. The small angle data were obtained using a Nanostar small-angle X-ray scattering (SAXS) diffractometer equipped with a high-power point focus $\mathrm{Cu} \mathrm{K} \alpha$ source. The scanning electron microscopy (SEM) images were obtained using Hitachi S-5200 at $5 \mathrm{kV}$. High-resolution transmission electron microscope (HRTEM) imaging and energy dispersive $\mathrm{X}$-ray (EDX) spectroscopy were performed at the Canadian Centre for Electron Microscopy at McMaster University using a FEI Titan 80$300 \mathrm{keV}$ electron microscope. TEM samples were prepared by first grinding a small amount of powder well in a mortar using ethanol and then drop-casting from ethanol solutions onto carbon-coated copper grids. UV-vis-NIR absorption spectra were collected using a Perkin-Elmer Lamda 900 spectrophotometer using a diffuse reflectance attachment. Sorption experiments were performed on a Quantachrome Autosorb$1 \mathrm{C}$ using $\mathrm{N}_{2}$ as the sorption gas at $77 \mathrm{~K}$. Five data points were selected for BET analysis from $P / P_{0}=0.1$. Solid-state $\mathrm{NMR}$ was performed on a Bruker Avance $200 \mathrm{MHz}$ spectrometer using a $7 \mathrm{~mm}$ zirconia rotor and magic-angle spinning (MAS) at a spinning frequency of $5000 \mathrm{~Hz} \cdot{ }^{29} \mathrm{Si}$ cross-polarized (CP) MAS NMR spectra were obtained using a $10 \mathrm{~ms}$ contact time. The ${ }^{13} \mathrm{C}$ cross-polarized (CP) MAS experiment was performed with a $1 \mathrm{~ms}$ contact time using composite pulse proton decoupling. Fourier transform infrared (FTIR) spectroscopy was performed on a Perkin-Elmer Spectrum One FTIR spectrometer. Solid samples were mixed with $\mathrm{KBr}$, ball milled into a fine powder, and pressed into a dense pellet for analysis. XPS were acquired using a Thermo Scientific Theta Probe utilizing monochromatic $\mathrm{Al} \mathrm{K} \mathrm{K}_{\alpha}$ radiation.

\section{RESULTS AND DISCUSSION}

Because the PMHS framework is thought to be stabilized for the most part by silanol groups hydrogen-bonded to silicon hydride groups in the framework denoted $\mathrm{SiH} \cdot \cdots \mathrm{HOSi}$, the question of mesostructural collapse upon reaction with $\operatorname{Ag}(\mathrm{I})$ is of prime concern. This would be most immediately evident in the morphology of the individual PMHS microspheres, which would certainly show distortions if reaction with $\mathrm{Ag}(\mathrm{I})$ compromises the structural integrity of the open framework. Figure 1 shows the SEM images of a PMHS sample before and after $\operatorname{Ag}(0)$ loading. The SEM images depict spherical particles with a size range of $50 \mathrm{~nm}$ to a few micrometers, Figure 1a, with no visible effect on the sphere shape after reaction with $\mathrm{Ag}(\mathrm{I})$. Smaller and/ 

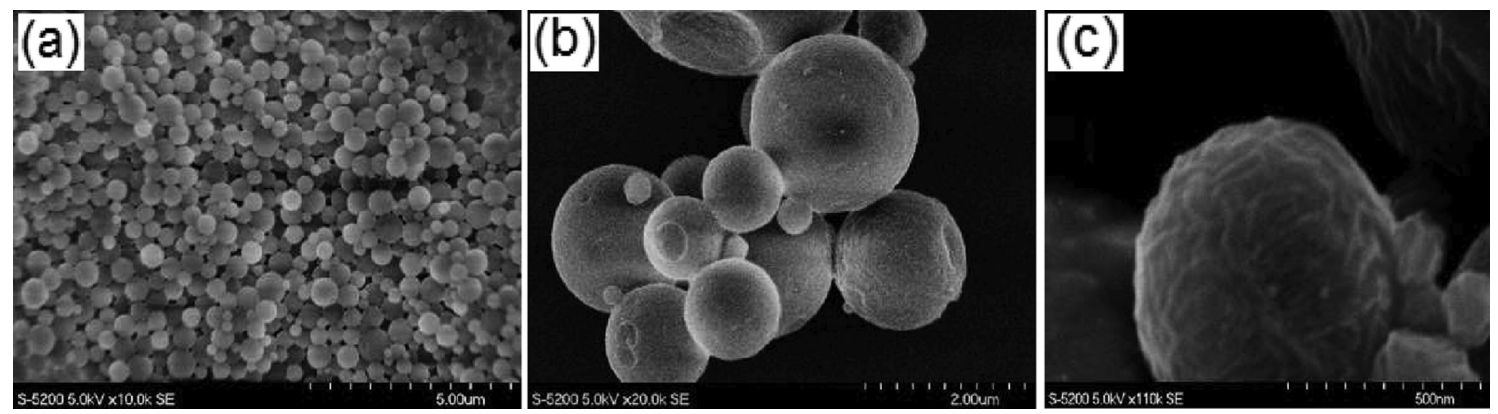

Figure 1. SEM images of the PMHS before (a), scale bar is $5.0 \mu \mathrm{m}$, and after $\mathrm{AgNO}_{3}$ reaction in water-ethanol mixtures $(\mathrm{b}, \mathrm{c})$, scale bar is $2.0 \mu \mathrm{m}$ and $500 \mathrm{~nm}$, respectively.

or more uniform spheres can also be obtained by carefully adjusting the $\mathrm{pH}$ of the synthesis solution of the PMHS. Incorporation of Ag nanoparticles apparently makes the PMHS microspheres more conductive, as demonstrated by the better defined surface morphology in the SEM image upon reaction with $\mathrm{Ag}(\mathrm{I})$ ions (Figure $1 \mathrm{~b}$ ). The worm-shaped surface features become better resolved in the SEM images after $\operatorname{Ag}(0)$ deposition into the pores and onto the pore walls.

The SAXS pattern of the as-synthesized PMHS displays one broad diffraction line at approximately $0.4^{\circ}$, corresponding to a $20 \mathrm{~nm} d$-spacing; see Figure 2a. The diffraction line is enhanced upon SDA removal, but loses much intensity after loading with silver. The enhancement of the diffraction line(s) of the PMHS upon removal of the SDA has also been observed in many mesoporous silica materials synthesized at room temperature (RT) and templated with various Pluronic surfactants. ${ }^{33}$ The apparent loss of mesostructure order upon silver loading seen in the SAXS pattern is likely due to the random distribution of the silver nanoparticles in the pore walls and channels causing inhomogeneous broadening of diffraction lines but not to mesostructure collapse of the host. The diffraction lines in the WAXS pattern originate from crystalline $\mathrm{Ag}(0)$ nanoparticles; see Figures $2 \mathrm{~b}$ and $\mathrm{S} 1$. The sharp lines superimposed over the broad lines, see inset in Figure $2 b$, are due to larger worm-shaped $\operatorname{Ag}(0)$ nanoparticles. The broad features are most likely due to smaller $\operatorname{Ag}(0)$ nanoparticles in the channels of the PMHS microspheres.

The reaction between the PMHS microspheres and $\mathrm{Ag}^{+}$ions in aqueous ethanol is fast and liberates $\mathrm{H}_{2}$ gas; see later. During the reaction, the white powder turns light yellow, then orange, then brown or gray, and finally black within 20-30 min of contact with the $\mathrm{Ag}^{+}$ion solution. This change in optical behavior is directly correlated to differences in $\operatorname{Ag}(0)$ species present at different sites within the mesoporous samples. UV-vis-NIR diffuse reflectance spectra were obtained from a series of samples prepared in this way, Figures 3 and S2. The samples become brown if the $\mathrm{Ag}^{+}$ion loading is carried out before SDA removal or brown-yellow if the reaction is stopped within $5 \mathrm{~min}$ by filtering and washing the samples. If the SDA is not removed prior to $\mathrm{Ag}^{+}$ ion loading, only broad diffraction lines originating from the 3-4 $\mathrm{nm} \operatorname{Ag}(0)$ nanoparticles embedded within the pore walls are observed, Figure S1. The black samples display continuous absorption between 200 and $2500 \mathrm{~nm}$, with a very weak and broad plasmon peak centered at $390 \mathrm{~nm}$, which is characteristic of silver nanoparticles; see Figure S2. The gray samples also display broad absorption between 200 and $2500 \mathrm{~nm}$ but peaking around $340 \mathrm{~nm}$ and in the NIR region, Figure 3. The plasmon peak is observed at around $335-355 \mathrm{~nm}$, depending on the degree of $\mathrm{Ag}^{+}$ion loading, and originates from small $\mathrm{Ag}(0)$ nanoparticles $(2-3 \mathrm{~nm})$. Another broad feature in the NIR region is due to elongated $\mathrm{Ag}(0)$ nanoparticles, and the other high energy peak, observed at around $265-280 \mathrm{~nm}$, originates from the molecular $\operatorname{Ag}(0)$ nanoclusters. ${ }^{12,34}$

The broad absorption (black color) in the NIR region must originate from worm-shaped $\operatorname{Ag}(0)$ nanoparticles growing within and adopting the shape of the pores of the PMHS microspheres; see Figure 4a. The peak position of the NIR absorption depends on the length $(L)$ to width $(D)$ ratio of the worm-shaped $\operatorname{Ag}(0)$ nanoparticles, and as the aspect ratio $(L / D)$ increases, this peak displays the expected red shift. ${ }^{34,35}$ The broadness of this feature likely originates from the nonuniform size and distribution of these worm-shaped nanoparticles, which most likely originates from pore-directed aggregation of smaller $\operatorname{Ag}(0)$ nanoparticles. This aggregation creates plasmonic $\operatorname{Ag}(0)$ worm-shaped nanoparticle clusters. These species can absorb a broad range of electromagnetic radiation in the UV-vis-NIR regions due to transitions among coupled nanoparticle states (akin to transverse and longitudinal conduction electron resonance modes in silver nanorods). ${ }^{35}$

The silver-loaded PMHS materials were further analyzed using different TEM techniques to elucidate the nature of the $\operatorname{Ag}(0)$ nanoparticles and to determine whether changes to the mesostructure occurred during the reaction with $\mathrm{Ag}(\mathrm{I})$ solutions; see Figures 4, 5, and S3. Samples of PMHS were exposed to Ag(I) aqueous ethanol solutions of low and high concentration, to compare how the loading of $\operatorname{Ag}(0)$ determines the silver nanoparticle size, shape, and distribution in the PMHS host. Figure $4 \mathrm{a}$ shows a high angle annular dark field (HAADF) TEM image of a representative sample. The image clearly shows larger worm-shaped $\operatorname{Ag}(0)$ nanoparticles and smaller spherical-shaped $\operatorname{Ag}(0)$ nanoparticles loaded within the pores of the mesoporous silica, an observation consistent with the PXRD data. The EDX spectrum of the large, worm-shaped nanoparticles displays mainly an $\mathrm{Ag}$ peak with weak $\mathrm{Si}$ and $\mathrm{O}$ peaks due to the surrounding silica matrix. Figure $4 \mathrm{a}-\mathrm{d}$ shows the worm-shaped mesopore morphology of the silica matrix, clearly revealing the pores and pore walls with diameter and thickness around 6.9 and $9.7 \mathrm{~nm}$, respectively, as indicated in Figure 4d. This is consistent with our previous report on the structure of the PMHS host material. ${ }^{32}$ The mesopores are clearly present after silver loading, which indicates that the reaction with $\operatorname{Ag}(\mathrm{I})$ does not cause collapse of the PMHS host. By comparing the images in Figure 4c and $f$, it is clear that the degree of loading depends on the $\mathrm{Ag}(\mathrm{I})$ concentration. 
(a)

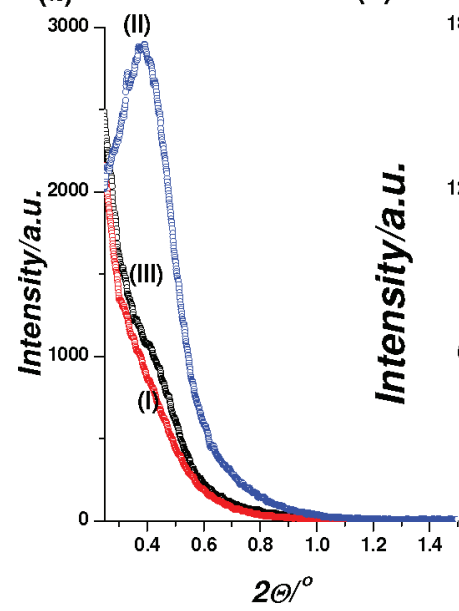

(b)

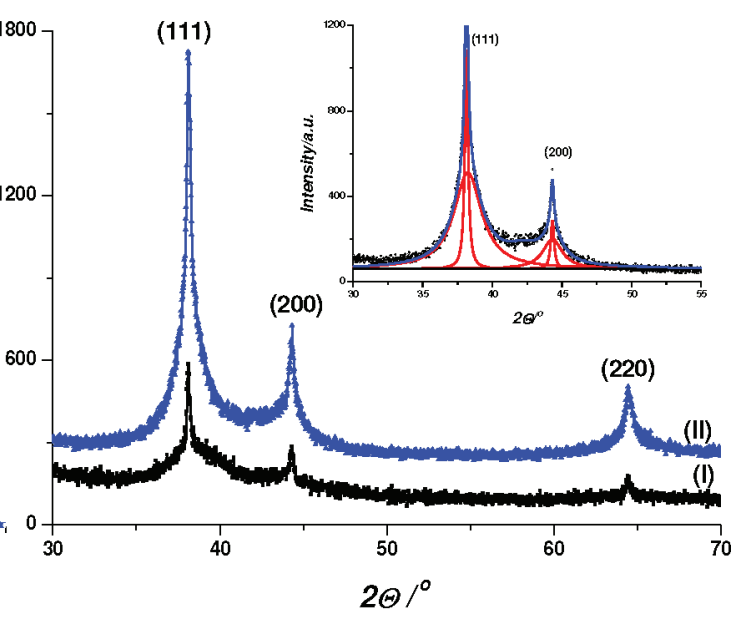

Figure 2. (a) SAXS pattern of as-synthesized PMHS (I), after surfactant removal (II), and $\mathrm{Ag}^{+}-$loaded sample in a $0.27 \mathrm{Ag}^{+} / \mathrm{SiH}$ water-ethanol solution (III). (b) WAXS pattern of $\mathrm{Ag}^{+}$-loaded PMHS at low (I) and high (II) loadings (inset is the fitting of the (111) and (200) lines of Ag(0) nanoparticles).

(a)

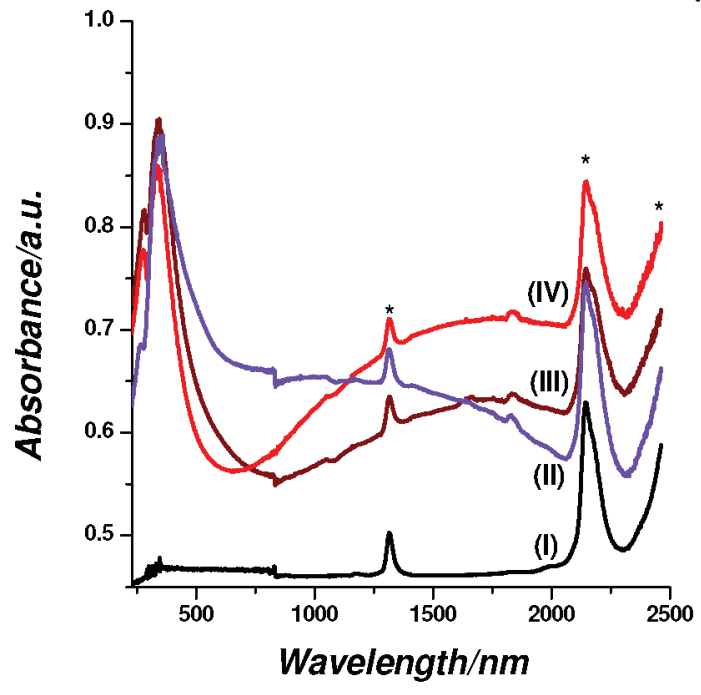

(b)

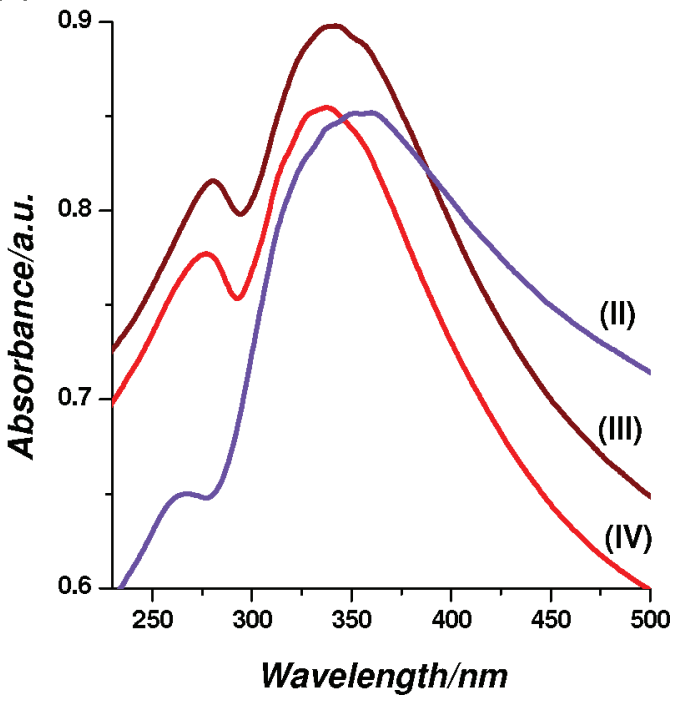

Figure 3. (a) UV-vis-NIR diffuse reflectance spectra of (I) quartz (sample holder), and $\mathrm{PMHS}$ reacted in $\mathrm{AgNO}_{3}$ aqueous ethanol solution with a $\mathrm{Ag}^{+} / \mathrm{SiH}$ mole ratio of (II) 0.1, (III) 0.45 , and (IV) 1.0 , and (b) the expanded $\mathrm{Ag}(0)$ plasmon region of the same samples.

The worm-shaped $\operatorname{Ag}(0)$ nanoparticles have a diameter of approximately $10-15 \mathrm{~nm}$, depending on the pore size of the mesoporous silica matrix. The length of the large worm-shaped $\operatorname{Ag}(0)$ nanoparticles ranges from 50 to $110 \mathrm{~nm}$. The shape and diameter of these worm-like $\operatorname{Ag}(0)$ nanoparticles imply that they are growing outward from within the worm-shaped pores, mirroring their shape as they grow. Figure 5a shows part of a worm-shaped $\operatorname{Ag}(0)$ nanoparticle that is composed of four smaller $\operatorname{Ag}(0)$ nanoparticle components linked together. The magnified image in Figure $5 \mathrm{~b}$ clearly shows lattice planes, implying that the $\operatorname{Ag}(0)$ nanoparticles are crystalline. The fast Fourier transform of the image in Figure 5d displays spots originating from the (111) lattice planes of $\operatorname{Ag}(0)$, which confirms that the Ag nanoparticles are indeed crystalline. This is in agreement with the observed WAXS patterns, Figure $2 \mathrm{~b}$. Additionally, the lattice fringes are oriented in different directions for each $\operatorname{Ag}(0)$ nanoparticle, which points to pore-directed aggregation of individual $\operatorname{Ag}(0)$ nanocrystals instead of continuous growth of a single nanocrystal. When $\mathrm{Ag}^{+}$ions diffuse into the pores, they get reduced to $\mathrm{Ag}(0)$ by the $\mathrm{SiH}$ sites and form small $\mathrm{Ag}(0)$ nanoparticles, which aggregate into larger worm-shaped nanoparticles most likely forcibly extruded out of the pores by the production of $\mathrm{H}_{2}$ gas within them; see later.

To further understand the $\mathrm{Ag}(\mathrm{I})$ reduction and what is presumed to be associated hydrogen elimination reactions, we recorded a series of FTIR, Raman, and ${ }^{29} \mathrm{Si}$ NMR spectra of the samples before and after $\mathrm{Ag}(\mathrm{I})$ reaction. The reducing host, PMHS, displays a sharp IR peak at around $2260 \mathrm{~cm}^{-1}$, originating from the $\mathrm{Si}-\mathrm{H}$ stretching mode, which can be used to monitor progress of the reduction process. Figure 6a shows a series of FTIR spectra of the PMHS before and after reacting with $\mathrm{AgNO}_{3}$. The reactions were carried out at three different $\mathrm{Ag}^{+}$ion concentrations such that the $\mathrm{Ag}^{+} / \mathrm{SiH}$ mole ratio, $x$, was $0.10,0.45$, and 1.00 . The $\nu \mathrm{Si}-\mathrm{H}$ peak intensity 

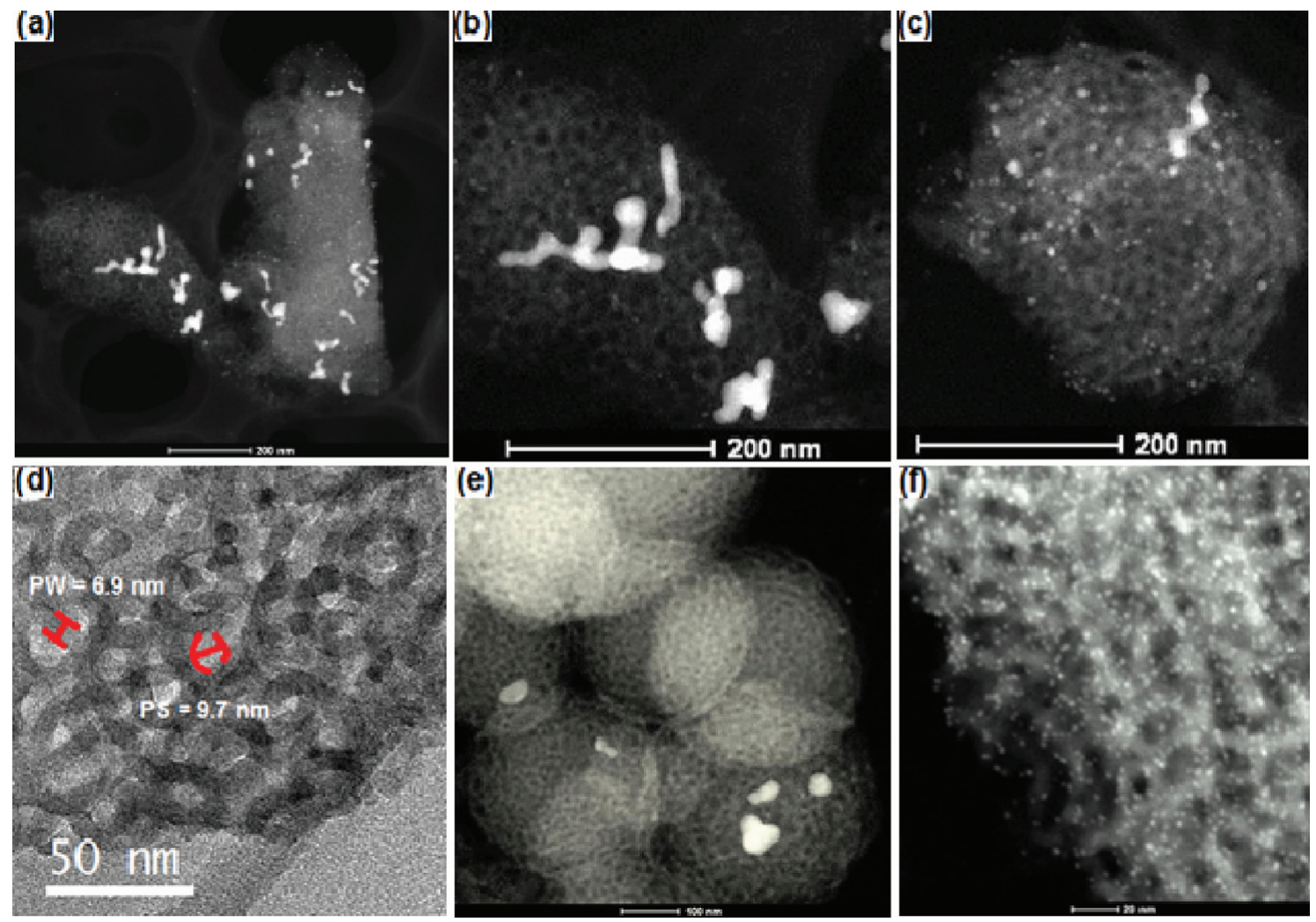

Figure 4. HAADF TEM images of the low $\mathrm{Ag}^{+}$ion-loaded PMHS sample $(\mathrm{a}-\mathrm{c})$ and $(\mathrm{d})$ the TEM image and the high $\mathrm{Ag}^{+}$ion-loaded PMHS sample (e and f). PW and PS stand for pore wall and pore size, respectively.
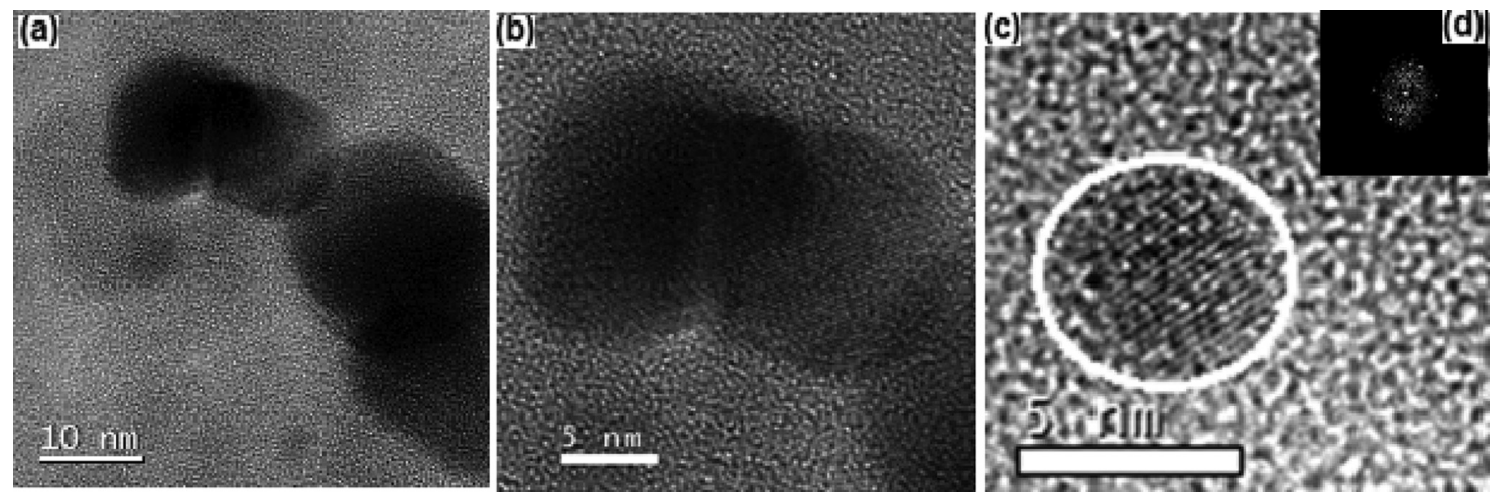

Figure 5. TEM images of ( $\mathrm{a}$ and $\mathrm{b}$ ) a worm-shaped $\operatorname{Ag}(0)$ nanoparticle at two different magnifications and $(\mathrm{c})$ an individual $\mathrm{Ag}(0)$ nanoparticle and (d) FFT of the TEM image in panel (c).

decreases by more than $90 \%$ and by an amount independent of the $\mathrm{AgNO}_{3}$ concentration; even at $x=0.10$, almost all of the $\mathrm{SiH}$ species are consumed. This indicates that there must be more than one type of reaction that consumes $\mathrm{SiH}$ and converts it into $\mathrm{SiOH}$. The remaining $10 \% \mathrm{SiH}$ is likely associated with the inaccessible $\mathrm{SiH}$ sites buried in the pore wall.

Figure $6 \mathrm{~b}$ shows Raman spectra of an unreacted PMHS together with two samples reacted with a water-ethanol solution of $\mathrm{AgBF}_{4}$. The Raman spectrum of PMHS displays a very intense and sharp peak at $2260 \mathrm{~cm}^{-1}$ due to the $\mathrm{Si}-\mathrm{H}$ stretching mode, which almost completely disappears upon reaction with $\mathrm{Ag}(\mathrm{I})$ species (not shown). The labels in the spectra in Figure 6b indicate the acids used during the synthesis and SDA extraction steps of the preparation of the corresponding PMHS samples. The sharp peaks in the spectrum of PMHS are from the unhydrolyzed ethoxy sites $\left(\mathrm{Si}-\mathrm{OC}_{2} \mathrm{H}_{5}\right)$ in the pore walls, $\delta$ $\mathrm{SiH}$ deformation modes $\left(800-900 \mathrm{~cm}^{-1}\right)$, and silica species (1000-1200 $\left.\mathrm{cm}^{-1}\right)$. These sharp peaks completely disappear with the $\operatorname{Ag}(\mathrm{I})$ reaction, and new broad features with intense peaks at around 230 and $165 \mathrm{~cm}^{-1}$ appear, indicating the formation of $\operatorname{Ag}(0)$ nanoclusters. ${ }^{36}$ The broad feature at $230 \mathrm{~cm}^{-1}$ could be attributed to the presence of AgCl species. ${ }^{37}$ To eliminate the possibility of $\mathrm{AgCl}$ formation, we also prepared PMHS samples using nitric acid (where the synthesis and washing steps were carried out using $\mathrm{HNO}_{3}$ ) and performed silver loading from $\mathrm{AgNO}_{3}$ or $\mathrm{AgBF}_{4}$ solutions. However, the peak at around 
(a)

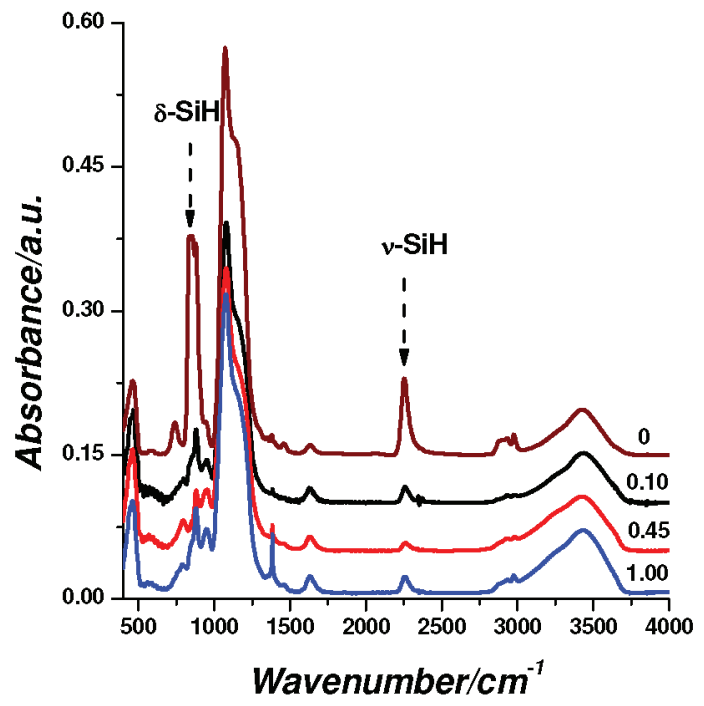

(b)

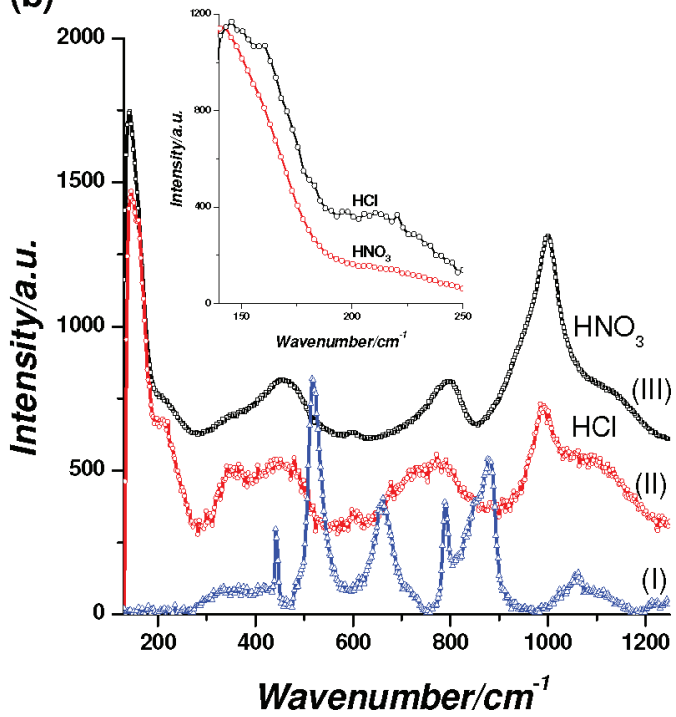

Figure 6. (a) FTIR spectra of PMHS before and after $\mathrm{AgNO}_{3}$ reaction with a water-ethanol solution of $\mathrm{Ag}^{+} / \mathrm{SiH}$ mole ratio, $x$, as indicated on the spectra. (b) Raman spectra of (I) PMHS and (II and III) after Ag(I) reaction of the same sample (labels indicate the acids used in the preparation of PMHS powders).

(a)

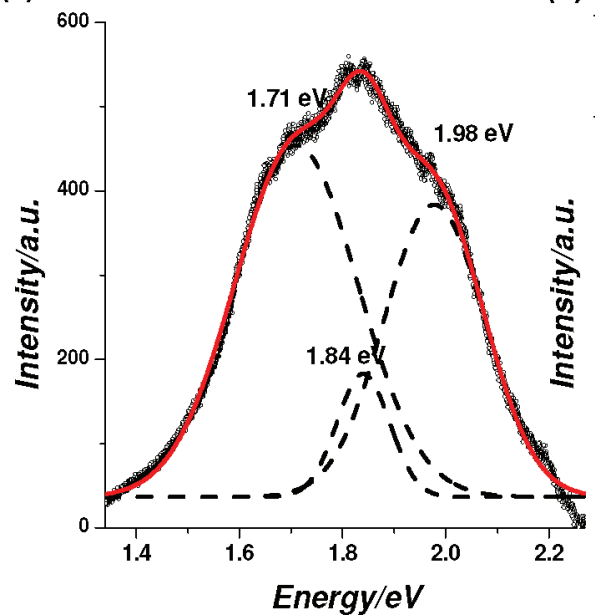

(b)

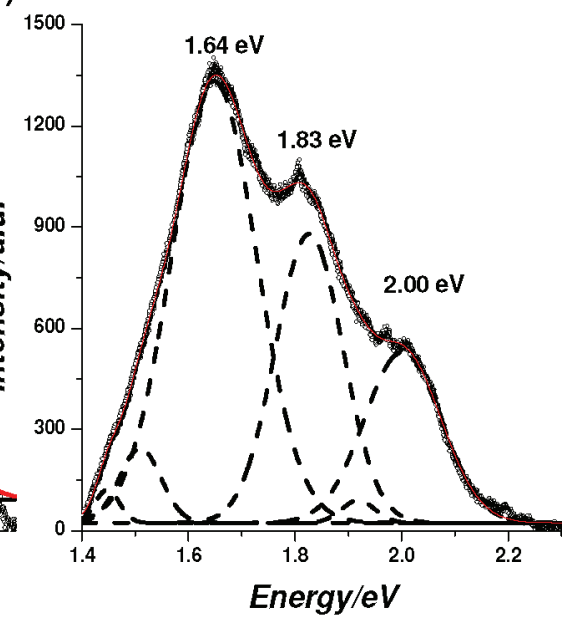

Figure 7. Laser excited photoluminescence spectra of a low $\mathrm{Ag}(0)$-loaded PMHS as a function of laser exposure time: (a) first run and (b) second run. The laser excitation wavelength is $532 \mathrm{~nm}$. Broken lines are the convolution of the PL spectra.

$230 \mathrm{~cm}^{-1}$ does not completely disappear in the spectrum, see Figure $6 \mathrm{~b}$, top spectrum, indicating that it also originates from the $\operatorname{Ag}(0)$ clusters. The partially loaded $\operatorname{Ag}(\mathrm{I})$ samples also display photoluminescence (PL) upon excitation with the Raman laser $(532 \mathrm{~nm})$ and provide evidence for the formation of molecular $\operatorname{Ag}(0)$ nanoclusters. Figures $7 \mathrm{a}, \mathrm{b}$ shows the PL spectra after two subsequent exposures of an $\mathrm{Ag}(\mathrm{I})$-loaded sample to a Raman laser operating at $532 \mathrm{~nm}(2.33 \mathrm{eV})$. The $x$-axis has been plotted on an energy scale $(\mathrm{eV})$ to show photoluminescence (PL) frequencies. The PL frequency shifts to lower energy upon a second exposure to the Raman laser and then remains stable under $532 \mathrm{~nm}$ laser illumination. This behavior can be related to some photolytically or photothermally induced rearrangement of the $\operatorname{Ag}(0)$ species and their growth to a more stable $\operatorname{Ag}(0)$ nanocluster. It is well established that most $\operatorname{Ag}(0)$ nanoparticles either do not emit or emit only very weakly. ${ }^{20,21}$ However, we always observe orange-red emission at low $\mathrm{Ag}^{+}$ion loadings. Because we also observe what we believe to be Raman active $v \mathrm{Ag}-\mathrm{Ag}$ stretching modes characteristic of $\operatorname{Ag}(0)$ nanoclusters, the likely origin of the PL are these $\operatorname{Ag}(0)$ clusters. $^{14,36}$ These molecular $\operatorname{Ag}(0)$ nanoclusters are most likely stabilized in micropores contained within the pore walls of PMHS, where the majority of the reducing $\mathrm{SiH}$ species are known to be located.

The porous nature of the as-synthesized and $\operatorname{Ag}(0)$-loaded PMHS materials was investigated using gas adsorption, with special attention paid to the changes in specific surface area, pore volume, and microporosity. The $\mathrm{N}_{2}$ adsorption-desorption isotherms of PMHS, before and after $\mathrm{Ag}(\mathrm{I})$ reaction under various conditions, show Type IV curves with $\mathrm{H} 2$ hysteresis characteristic of large-pore, moderately ordered mesoporous materials, Figure 8a. From the sorption data, the BET specific surface area, cumulative pore volume, and $\mathrm{BJH}$ pore diameter can be obtained 
(a)

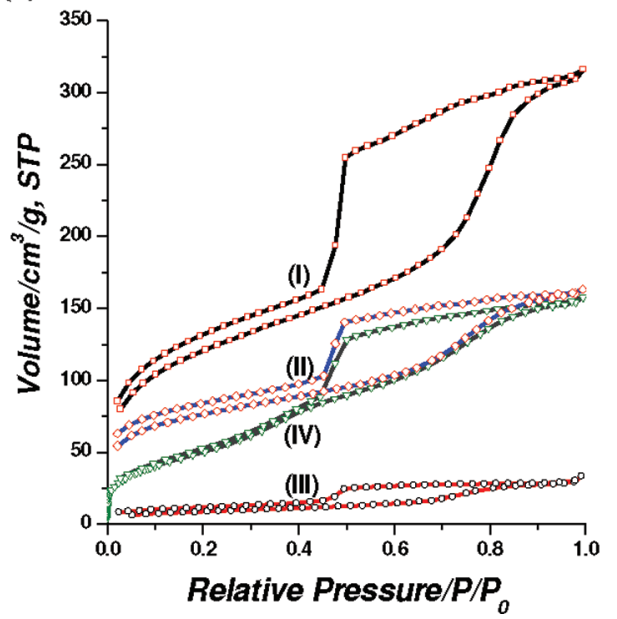

(b)

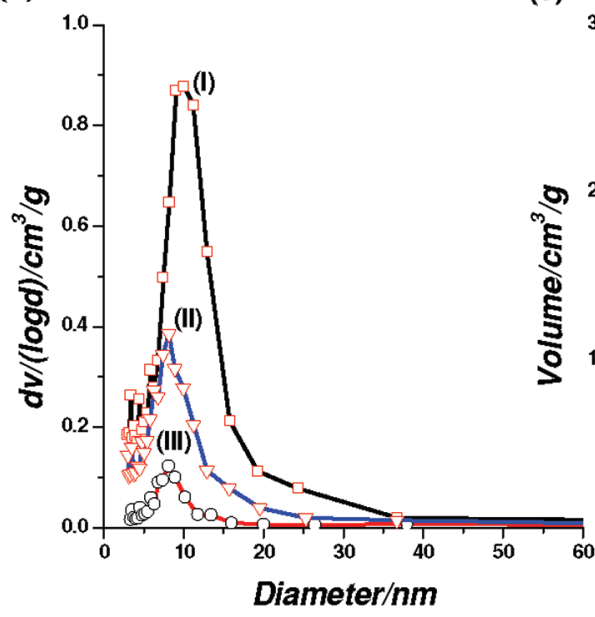

(c)

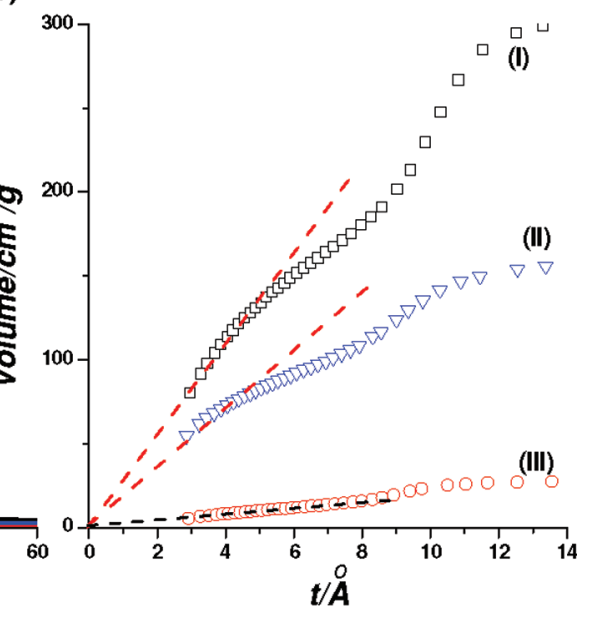

Figure 8. (a) Nitrogen adsorption-desorption isotherms before (I) and after Ag(I) reactions of PMHS with $x=0.66$ for (II) $5 \mathrm{~min}$ and (III) $30 \mathrm{~min}$ and (IV) with $x=0.23$ for $30 \mathrm{~min}$, (b) the BJH pore size distribution curves, and (c) $t$-plots of the same samples.

Table 1. Reaction Conditions $\left(\mathrm{Ag}^{+} / \mathrm{SiH}\right.$ Mole Ratio in Aqueous Ethanol, $x$, and Time in minutes), BET Specific Surface Area, Cumulative Pore Volume, and BJH Pore Diameter for (I) PMHS before Reaction with $\operatorname{Ag}(\mathrm{I})$ and (II-IV) PMHS after Reaction with $\operatorname{Ag}(\mathrm{I})$ under Various Conditions

\begin{tabular}{ccccc} 
sample & $\begin{array}{c}\text { reaction } \\
\text { conditions } \\
(x, \text { time }(\mathrm{min}))\end{array}$ & $\begin{array}{c}\text { BET } \\
\text { SSA } \\
\left(\mathrm{m}^{2} / \mathrm{g}\right)\end{array}$ & $\begin{array}{c}\text { pore } \\
\text { volume } \\
\left(\mathrm{cm}^{3} / \mathrm{g}\right)\end{array}$ & $\begin{array}{c}\text { pore } \\
\text { diameter } \\
(\mathrm{nm})\end{array}$ \\
I & $0.00,0$ & 430 & 0.48 & 9.0 \\
II & $0.66,5$ & 266 & 0.25 & 8.1 \\
III & $0.66,30$ & 49 & 0.07 & 5.1 \\
IV & $0.23,30$ & 191 & 0.24 & 5.0 \\
\hline
\end{tabular}

(see Table 1). The BET surface area and pore volume of the unreacted PMHS (I) are typical of mesoporous silica with walls 6-7 nm thick. Upon reaction with $\mathrm{AgBF}_{4}$ for $5 \mathrm{~min}$ at $x=0.66$ (II), $30 \mathrm{~min}$ at $x=0.23$ (IV), and $30 \mathrm{~min}$ at $x=0.66$ (III), a stepwise decrease in surface area and pore volume is observed that corresponds to increased silver loading. The $\mathrm{BJH}$ pore diameter (Figure 8b, Table 1) also decreases with increased silver loading yet is the same for different loadings at the same reaction time. This indicates that as silver loading increases, larger and more aggregated $\operatorname{Ag}(0)$ nanoparticles begin to block the mesopores. This is a time-dependent process, as indicated by the difference in the values obtained for (II), which was reacted at $x=0.66$ for $5 \mathrm{~min}$, and (III), which was reacted at $x=0.66$ for $30 \mathrm{~min}$; a longer reaction time results in higher silver loading. The $t$-plots for (I) - (IV) (Figure 8c) show positive intercepts of progressively decreasing values. In a $t$-plot, the intercept of the best-fit line indicates the amount of micropore volume present in a given sample. A downward deviation of the data points from a line drawn through the origin to the first data point indicates the presence of micropores, while an upward deviation indicates the presence of only mesopores. ${ }^{38}$ For PMHS, the micropore volume is present within the pore walls of the material. The decrease in the value of the intercept with increased silver loading in these three samples corresponds to a loss of microporosity. For (II) and (IV), where the BET specific surface areas and pore

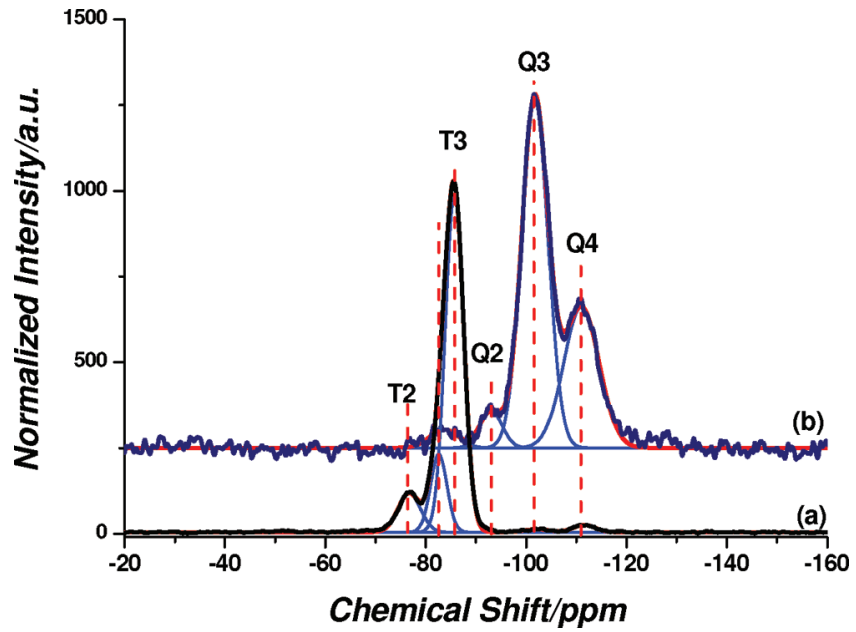

Figure 9. ${ }^{29}$ Si MAS NMR spectra of PMHS (a) before and (b) after reaction with $\mathrm{AgNO}_{3}$.

volumes are similar, the $t$-plots show a significant difference: (II) shows evidence of microporosity, while (IV) does not. This indicates that the loss of microporosity is likely due to the growth of $\operatorname{Ag}(0)$ nanoclusters in the walls of the material. Collectively, the sorption data show that the internal and external surface $\mathrm{SiH}$ groups react with $\operatorname{Ag}(\mathrm{I})$ to produce $\operatorname{Ag}(0)$ nanoparticles, where the diffusion of $\operatorname{Ag}(\mathrm{I})$ into and its reduction within the pore walls fill the micropores and suggests that nanoclusters might diffuse out into the mesopores and aggregate further to nanoparticles to complete the process.

The results obtained from the ${ }^{29} \mathrm{Si}$ CP MAS NMR spectra complement the FTIR data and give valuable information about the reduction process; see Figure 9. The unreacted PMHS displays two signals at -76.7 and $-85.8 \mathrm{ppm}$ (with a shoulder at $-82.8 \mathrm{ppm})$, which are assigned to $\mathrm{T}_{2}\left(\mathrm{H}-\mathrm{SiO}_{2}(\mathrm{OH})\right)$ and $\mathrm{T}_{3}\left(\mathrm{H}-\mathrm{SiO}_{3}\right)$ sites, respectively, Figure 9a. A small amount of $\mathrm{Q}_{3}$ $\left(\mathrm{HOSiO}_{3}\right)$ and $\mathrm{Q}_{4}\left(\mathrm{SiO}_{4}\right)$ sites at -102.6 and $-111.6 \mathrm{ppm}$, respectively, are also observed and are due to the hydrolysis of a small amount of $\mathrm{SiH}$ sites (less than 5\%). ${ }^{32}$ Upon reaction with $\mathrm{Ag}(\mathrm{I})$ species, the $\mathrm{T}$ species are almost completely replaced by $\mathrm{Q}$ 


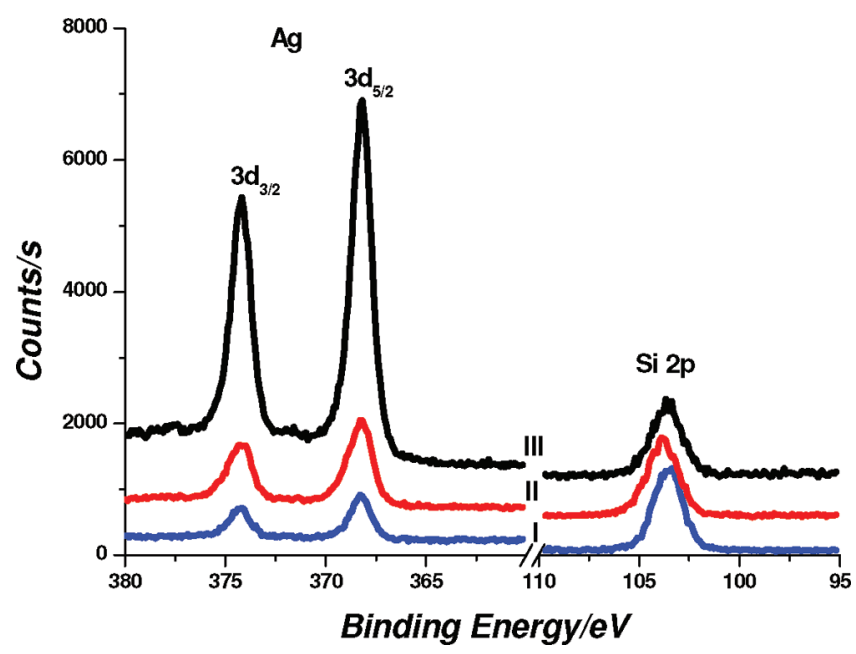

Figure 10. High-resolution XPS spectra of the samples I, II, and III in the $\mathrm{Si}(2 \mathrm{p})$ and $\mathrm{Ag}(3 \mathrm{~d})$ regions.

species, predominantly $\mathrm{Q}_{3}$ isolated silanols, Figure 9b. This is consistent with the results observed in FTIR and suggests that two competing processes, the hydrolysis of $\mathrm{SiH}$ sites in the PMHS and the reduction of $\mathrm{Ag}(\mathrm{I})$ by $\mathrm{SiH}$, occur in this system and lead to the near-complete conversion of all $\mathrm{SiH}$ sites into $\mathrm{SiOH}$ sites. Because the dominant species is $\mathrm{Q}_{3}$, significant condensation has not occurred, and thus the loss of micropores due to increased silanol condensation upon reaction with $\mathrm{Ag}(\mathrm{I})$ can be ruled out. Given a wall thickness of ca. $6.9 \mathrm{~nm}$, it is reasonable to presume that the majority of the $\mathrm{SiH}$ sites are buried within the pore walls of PMHS. The sharp decrease of the $\mathrm{SiH}$ peak means that $\mathrm{Ag}^{+}$ions can readily diffuse into confined spaces within the pore walls and react with these buried $\mathrm{Si}-\mathrm{H}$ sites to create molecular photoluminescent $\operatorname{Ag}(0)$ nanoclusters therein.

There appears to exist two reactions concurrently occurring in the reductive nucleation and growth of $\mathrm{Ag}^{+}$ions to $\mathrm{Ag}(0)$ aggregates within the pore spaces of PMHS. The first produces $\mathrm{H}_{2}$ (eq 1), where the $\mathrm{Ag}(\mathrm{I})$ or $\mathrm{Ag}(0)$ species likely catalyzes the process, and the second results in the formation of $\operatorname{Ag}(0)$ nanoparticles (eq 2), and both reactions lead to the formation of $\mathrm{SiOH}$ sites as observed in the bulk polyhydrido silica. ${ }^{39,40}$ The first reaction occurs vigorously, producing gaseous $\mathrm{H}_{2}$ that may enhance the aggregation of $\operatorname{Ag}(0)$ nanoparticles to produce worm-shaped nanoparticles.

$$
\begin{aligned}
& \text { meso- } \mathrm{O}_{1.5} \mathrm{Si}-\mathrm{H}(\mathrm{s}) \\
& +\mathrm{H}_{2} \mathrm{O}(\mathrm{l}) \rightarrow \text { meso- } \mathrm{O}_{1.5} \mathrm{Si}-\mathrm{OH}(\mathrm{s})+\mathrm{H}_{2}(\mathrm{~g}) \\
& \begin{array}{l}
\text { meso- } \mathrm{O}_{1.5} \mathrm{Si}-\mathrm{H}(\mathrm{s})+\mathrm{Ag}^{+}(\mathrm{aq}) \\
\quad+\mathrm{H}_{2} \mathrm{O}(\mathrm{l}) \rightarrow \text { meso- } \mathrm{O}_{1.5} \mathrm{Si}-\mathrm{OH}(\mathrm{s})+\mathrm{Ag}(\mathrm{s}) \\
\quad+\mathrm{H}^{+}(\mathrm{aq})+1 / 2 \mathrm{H}_{2}(\mathrm{~g})
\end{array}
\end{aligned}
$$

To further confirm and to quantify the $\mathrm{H}_{2}$ elimination (eq 1 ) and reduction (eq 2 ) reactions, we also recorded the XPS spectra of three samples that were reacted either with two different solution of $\operatorname{Ag}(\mathrm{I})$ with two different concentrations or over different time periods. The survey scans of all of the samples display $\mathrm{Si}, \mathrm{O}, \mathrm{C}$, and $\mathrm{Ag}$ related signals (Figure S4(a)) with a trace amount of $\mathrm{F}$ (due to some unwashed $\mathrm{AgBF}_{4}$ ), showing the purity
Table 2. XPS Data of the Samples Obtained from the Reaction of PMHS in Aqueous Ethanol Solution of $\mathrm{AgBF}_{4}$

\begin{tabular}{cccc} 
sample & $\begin{array}{c}\text { XPS Ag/ } \\
\text { Si atomic ratio }\end{array}$ & $\begin{array}{c}\text { reaction conditions } \\
\left(\mathrm{SiH} / \mathrm{Ag}^{+} \text {mole ratio, }\right. \\
\text { time }(\mathrm{min}))\end{array}$ & $\begin{array}{c}\mathrm{Ag}(0) / \mathrm{Ag}(\mathrm{I}) \\
\% \text { conversion }\end{array}$ \\
I & 0.035 & $0.66(5)$ & $5.4^{a}$ \\
II & 0.071 & $0.23(30)$ & 30.6 \\
III & 0.309 & $0.66(30)$ & 46.7 \\
${ }^{a}$ Not a complete reaction. & & \\
\hline
\end{tabular}

of the samples. The high-resolution spectra in the $\mathrm{Si}(2 \mathrm{p}), \mathrm{C}(1 \mathrm{~s})$, $\mathrm{O}(1 \mathrm{~s})$, and $\mathrm{Ag}(3 \mathrm{~d})$ binding energy regions were recorded to identify the oxidation state of the silver species. Figure 10 shows the $\mathrm{Si}(2 \mathrm{p})$ and $\mathrm{Ag}(3 \mathrm{~d})$ regions of the XPS spectra of the three silver-loaded samples. The $\mathrm{Ag}(3 \mathrm{~d})$ region clearly shows that the silver particles are at zero oxidation state. Samples I and III were exposed to the same amount of $\mathrm{Ag}(\mathrm{I})$ solution for 5 and $30 \mathrm{~min}$, respectively. Samples II and III were reacted for $30 \mathrm{~min}$ in two different $\mathrm{Ag}(\mathrm{I})$ solutions; see Table 2 for details. Clearly increasing $\operatorname{Ag}(\mathrm{I})$ concentration in the reaction media and reaction duration enhance the $\operatorname{Ag}(0)$ loading. These findings and the results from FTIR and NMR spectra and $\mathrm{N}_{2}$ sorption measurements confirm that reactions 1 and 2 proceed with comparable rates. However, reaction 2, which leads to $\operatorname{Ag}(0)$ nanoparticles, becomes the dominant reaction with increasing $\operatorname{Ag}(\mathrm{I})$ concentration in the reaction mixture.

The production of gaseous $\mathrm{H}_{2}$ from both reactions 1 and 2 was confirmed by reacting the so produced $\mathrm{H}_{2}$ with an aqueous solution of hexachloroplatinic acid $\left(\mathrm{H}_{2} \mathrm{PtCl}_{6}\right)$, in which the $\mathrm{Pt}(\mathrm{IV})$ is reduced to $\mathrm{Pt}(0)$, according to reaction Scheme S1 (Supporting Information). The presence of water is also crucial for both reactions 1 and 2 . To verify this, we also carried the $\mathrm{Ag}(\mathrm{I})$ reduction for $1 \mathrm{~h}$ (and repeated for 1 day) in a nonaqueous media at three different $\mathrm{Ag}(\mathrm{I}) / \mathrm{SiH}$ mole ratios, $0.20,0.50$, and 1.00. The XPS survey scans of these three samples showed less than $2.0 \%$ silver loadings were produced (Figure S4(b)) independent of the $\operatorname{Ag}(\mathrm{I})$ concentration in the reaction media. It is likely that this small silver loading can be due to the presence of some adsorbed water and/or some trapped $\mathrm{Ag}(\mathrm{I})$ precursor in the PMHS, indicating that the reaction does not take place in the absence of water in the reaction media.

\section{CONCLUSION}

In this work, we have demonstrated for the first time that periodic mesoporous hydridosilica (meso- $\mathrm{HSiO}_{1.5}$ ), dubbed PMHS, can act as both a host and a reducing agent for $\mathrm{Ag}(\mathrm{I})$ ions to create photoluminescent $\operatorname{Ag}(0)$ molecular nanoclusters and plasmonic $\operatorname{Ag}(0)$ nanoparticles in its pore walls and on its pore surfaces, respectively. The reductive nucleation and growth of $\mathrm{Ag}^{+} \rightarrow \mathrm{Ag}^{0} \rightarrow \mathrm{ncAg}^{0}$ by $\mathrm{SiH}$ groups in the pore walls might be initiated by $\mathrm{SiH} \cdot \mathrm{AgOSi}$ whereby $\mathrm{Ag}^{+}$is captured by $\mathrm{SiOH}$ in the reduction zone of the $\mathrm{SiH}$ groups. More than $90 \%$ of the $\mathrm{Si}-\mathrm{H}$ groups are found to participate in these in situ reduction processes. The size, shape, and distribution of the $\operatorname{Ag}(0)$ nanoclusters and nanoparticles so formed depend on the loading of $\operatorname{Ag}(\mathrm{I})$ ions in the host material. The dominant $\operatorname{Ag}(\mathrm{I})$ ion reductive nucleation and growth process seems to occur with the majority $\mathrm{SiH}$ sites located within the pore wall to form molecular size NIR photoluminescent $\mathrm{Ag}(0)$ nanoclusters in the pore walls concurrently with the reaction of $\mathrm{Si}-\mathrm{H}$ on the pore 
surface of the PMHS microspheres to form lesser amounts of $\operatorname{Ag}(0)$ nanoparticles in the pores. The growth and formation of the largest, worm-shaped $\operatorname{Ag}(0)$ nanoparticles in the pores is shown to originate in a pore-directed aggregation process involving smaller individual $\operatorname{Ag}(0)$ nanoparticles rather than from the continuous growth of a single rod-shaped $\mathrm{Ag}(0)$ nanoparticle.

These findings bode well for a new genre of host-guest redox chemistry of the pore walls that exploits the reducing power of spatially confined $\mathrm{Si}-\mathrm{H}$ groups that are an inherent part of PMHS. Future work would explore the possibility of controlling the nucleation and growth processes to select certain sizes and shapes of the nanoparticles, the extension of the reducing power of PHMS to other metals, and the synthesis of alloy nanoparticles with tunable properties. In addition, a cornucopia of $\mathrm{Si}-\mathrm{H}$ reactions other than those leading to the production of metal nanoparticles from metal precursors should be explored, to examine the scope of applications available to this unique and highly promising material. These reactions can include organic and inorganic polymer and bioorganic chemistry of the pore walls.

\section{ASSOCIATED CONTENT}

S Supporting Information. Further characterization of the $\mathrm{Ag}(0)$-loaded meso- $\mathrm{HSiO}_{1.5}$ (includes more XRD, UV-vis absorption spectra, TEM, and XPS data). This material is available free of charge via the Internet at http://pubs.acs.org.

\section{AUTHOR INFORMATION}

\section{Corresponding Author}

dag@fen.bilkent.edu.tr; gozin@chem.utoronto.ca

\section{ACKNOWLEDGMENT}

G.A.O. is the Government of Canada Research Chair in Materials Chemistry and Nanochemistry. He thanks the Natural Sciences and Engineering Research Council (NSERC) of Canada for strong and sustained financial support of his research. Ö.D. thanks Bilkent University and the Turkish Academy of Science for financial support. We thank C. Andrei and G. de Silveira for the TEM measurements and I. Moudrakovski for assistance with SSNMR.

\section{REFERENCES}

(1) Kresge, C. T.; Leonowicz, M. E.; Roth, W. J.; Vartuli, J. C.; Beck, J. S. Nature 1992, 359, 710-712.

(2) (s) Asefa, T.; MacLachlan, M. J.; Coombs, N.; Ozin, G. A. Nature 1999, 402, 867-871. (b) Inagaki, S.; Guan, S.; Fukushima, Y.; Ohsuna, T.; Terasaki, O. J. Am. Chem. Soc. 1999, 121, 9611-9614. (c) Melde, B. J.; Holland, B. T.; Blanford, C. F.; Stein, A. Chem. Mater. 1999, $11,3302-3308$.

(3) Whitnall, W.; Asefa, T.; Ozin, G. A. Adv. Funct. Mater. 2005, $15,1696-1702$.

(4) (a) Asefa, T.; Kruk, M.; MacLachlan, M. J.; Coombs, N.; Grondey, H.; Jaroniec, M.; Ozin, G. A. J. Am. Chem. Soc. 2001, 123, 8520-8530. (b) Morell, J.; Güngerich, M.; Wolter, G.; Jiao, J.; Hunger, M.; Klar, P. J.; Fröba, M. J. Mater. Chem. 2006, 16, 2809-2818.

(5) (a) Jung, B. M.; Kim, M. S.; Kim, W. J.; Chang, J. Y. Chem. Commun. 2010, 46, 3699-3701. (b) Lofgreen, J. E.; Moudrakovski, I. L.; Ozin, G. A. ACS Nano 2011, 5, 2277-2287.

(6) Wang, W.; Lofgreen, J. E.; Ozin, G. A. Small 2010, 6, 2634-2642.

(7) Cai, W.; Zhang, Y.; Jia, J.; Zhang, L. Appl. Phys. Lett. 1998, 73, 2709-2711.
(8) Liong, M.; Angelos, S.; Choi, E.; Patel, K.; Stoddard, J. F.; Zink, J. I. J. Mater. Chem. 2009, 19, 6251-6257.

(9) Liong, M.; France, B.; Bradley, K. A.; Zink, J. I. Adv. Mater. 2009, 21, 1684-1689.

(10) Cortie, M. B.; McDonagh, A. M. Chem. Rev. 2011, 111, 37133735

(11) Peyser, L. A.; Vinson, A. E.; Bartko, A. P.; Dickson, R. M. Science 2001, 291, 103-106.

(12) Zheng, J.; Dickson, R. M. J. Am. Chem. Soc. 2002, 124, 13982 13983.

(13) Suarez, A. L.; Rivas, J.; Rodriguez, C. F.; Rodriguez, M. J.; Pastor, E.; Creus, A. H.; Oseroff, S. B.; Quintela, M. A. L. Angew. Chem., Int. Ed. 2007, 46, 8823-8827.

(14) Shang, L.; Dong, S. Chem. Commun. 2008, 1088-1090.

(15) Patel, S. A.; Richards, C. I.; Hsiang, J. C.; Dickson, R. M. J. Am. Chem. Soc. 2008, 130, 11602-11603.

(16) Huang, T.; Murray, R. W. J. Phys. Chem. B 2003, 107, 74347440.

(17) Yeshchenko, O. A.; Dmitruk, I. M.; Alexeenko, A. A.; Losytskyy, M. Y.; Kotko, A. V.; Pinchuk, A. O. Phys. Rev. B 2009, 79, 235438.

(18) Bakr, O. M.; Amendola, V.; Aikens, C. M.; Wenseleers, W.; Li., R.; Negro, L. D.; Schatz, G. C.; Stellacci, F. Angew. Chem., Int. Ed. 2009, 48, 5921-5926.

(19) Rao, T. I. B.; Pradeep, T. Angew. Chem., Int. Ed. 2010, 49, 3925-3929.

(20) Murphy, C. J.; Jana, N. R. Adv. Mater. 2002, 14, 80-82.

(21) Kelly, K. L.; Coronado, E.; Zhao, L. L.; Schatz, G. C. J. Phys. Chem. B 2003, 107, 668-677.

(22) Ozin, G. A.; Hugues, F. J. Phys. Chem. 1983, 87, 94-97.

(23) Wang, L. Z.; Shi, J. L.; Zhang, W. H.; Ruan, M. L.; Yu, J.; Yan, D. S. Chem. Mater. 1999, 11, 3015-3017.

(24) Besson, S.; Gacoin, T.; Rocolleau, C.; Boilot, J. P. Chem. Commun. 2003, 360-361.

(25) Dag, Ö.; Samarskaya, O.; Coombs, N.; Ozin, G. A. J. Mater. Chem. 2003, 13, 328-334.

(26) Hornebecq, V.; Antonietti, M.; Cardinal, T.; Delapierre, M. T. Chem. Mater. 2003, 15, 1993-1999.

(27) Takai, A.; Doi, Y.; Yamauchi, Y.; Kuroda, K. J. Phys. Chem. C 2010, 114, 7586-7593.

(28) Bois, L.; Chassagneux, F.; Desroches, C.; Battie, Y.; Destouches, N.; Gilon, N.; Parolo, S.; Stephan, O. Langmuir 2010, 26, 8729-8736.

(29) Qi, H.; Shopsowitz, K. E.; Hamad, W. Y.; MacLachlan, M. J. J. Am. Chem. Soc. 2011, 133, 3728-3731.

(30) (a) Li, L.; Shi, J. L.; Zhang, L. X.; Xiong, L. M.; Yan, J. N. Adv. Mater. 2004, 16, 1079-1082. (b) Xie, Y.; Quinlivan, S.; Asefa, T. J. Phys. Chem. C 2008, 112, 9996-10003. (c) Zhang, F.; Yin, J.; Chai, W.; Li, H. ChemSusChem 2010, 3, 724-727.

(31) Sun, J.; Ma, D.; Zhang, H.; Liu, X.; Bao, X.; Weinberg, G.; Pfader, N.; Su, D. J. Am. Chem. Soc. 2006, 128, 15756-15764.

(32) Xie, Z.; Henderson, E. J.; Dag, Ö.; Wang, W.; Lofgreen, J. E.; Kubel, C.; Scherer, T.; Brodersen, P. M.; Gu, Z.-Z.; Ozin, G. A. J. Am. Chem. Soc. 2011, 133, 5094-5102.

(33) Zhu, H.; Jones, D. J.; Zajac, J.; Roziere, J.; Dutartre, R. Chem. Commun. 2001, 2568-2569.

(34) Linnert, T.; Mulvaney, P.; Henglein, A.; Weller, H. J. Am. Chem. Soc. 1990, 112, 4657-4664.

(35) Chuntonov, L.; Haran, G. Nano Lett. 2011, 11, 2440-2445.

(36) Bosnick, K. A.; Haslett, T. L.; Fedrigo, S.; Moskovits, M.; Chan,

W. T.; Fournier, R. J. Chem. Phys. 1999, 111, 8867-8870.

(37) Roy, D.; Furtak, T. E. Phys. Rev. B 1986, 34, 5111-5117.

(38) Galarneau, A.; Cambon, H.; DiRenzo, F.; Fajula, F. Langmuir 2001, 17, 8328-8335.

(39) Corriu, R. J.; Leclercq, D. Angew. Chem., Inter. Ed. Engl. 1996, $35,1420-1436$

(40) Reed-Mundell, J. J.; Nadkarni, D. V.; Kunz, J. M.; Fry, C. W.; Fry, J. L. Chem. Mater. 1995, 7, 1655-1660. 